\title{
Discharge estimation combining flow routing and occasional measurements of velocity
}

\author{
G. Corato $^{1}$, T. Moramarco ${ }^{1}$, and T. Tucciarelli ${ }^{2}$ \\ ${ }^{1}$ Research Institute for Geo-hydrological Protection, National Research Council, via della Madonna Alta 126, \\ 06128 Perugia, Italy \\ ${ }^{2}$ Department of Civil, Environmental and Aerospace Engineering, University of Palermo, Italy, Viale delle Scienze, \\ 90128 Palermo, Italy
}

Received: 1 March 2011 - Published in Hydrol. Earth Syst. Sci. Discuss.: 10 March 2011

Revised: 16 September 2011 - Accepted: 19 September 2011 - Published: 26 September 2011

\begin{abstract}
A new procedure is proposed for estimating river discharge hydrographs during flood events, using only water level data at a single gauged site, as well as 1-D shallow water modelling and occasional maximum surface flow velocity measurements. One-dimensional diffusive hydraulic model is used for routing the recorded stage hydrograph in the channel reach considering zero-diffusion downstream boundary condition. Based on synthetic tests concerning a broad prismatic channel, the "suitable" reach length is chosen in order to minimize the effect of the approximated downstream boundary condition on the estimation of the upstream discharge hydrograph. The Manning's roughness coefficient is calibrated by using occasional instantaneous surface velocity measurements during the rising limb of flood that are used to estimate instantaneous discharges by adopting, in the flow area, a two-dimensional velocity distribution model. Several historical events recorded in three gauged sites along the upper Tiber River, wherein reliable rating curves are available, have been used for the validation. The outcomes of the analysis can be summarized as follows: (1) the criterion adopted for selecting the "suitable" channel length based on synthetic test studies has proved to be reliable for field applications to three gauged sites. Indeed, for each event a downstream reach length not more than $500 \mathrm{~m}$ is found to be sufficient, for a good performances of the hydraulic model, thereby enabling the drastic reduction of river cross-sections data; (2) the procedure for Manning's roughness coefficient calibration allowed for high performance in discharge estimation just considering the observed water levels and occasional measurements of maximum surface flow velocity during the
\end{abstract}

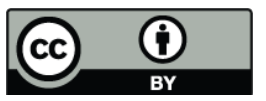

Correspondence to: G. Corato (g.corato@irpi.cnr.it) rising limb of flood. Indeed, errors in the peak discharge magnitude, for the optimal calibration, were found not exceeding $5 \%$ for all events observed in the three investigated gauged sections, while the Nash-Sutcliffe efficiency was, on average, greater than 0.95 . Therefore, the proposed procedure well lend itself to be applied for: (1) the extrapolation of rating curve over the field of velocity measurements (2) discharge estimations in different cross sections during the same flood event using occasional surface flow velocity measures carried out, for instance, by hand-held radar sensors.

\section{Introduction}

A fast and accurate estimation of the river discharge is of great interest for a large number of engineering applications such as real time flood forecasting and water resources management. Therefore, the knowledge of the rating curve at a river section is important for this purpose. Unfortunately, the reliability of a rating curve depends on the availability of a robust sample of velocity measurements, performed also for high stages, i.e. during high floods, and this seldom occurs. Indeed, besides the high cost of measurements, sampling of velocity points during high floods, especially in the lower portion of flow area, is quite difficult even because of the dangers that operators might face during the measurement. Therefore, in a well-equipped basin few gauged river sites can be established and, as a consequence, if additional river sites were of interest, for instance for water resource management and/or flood forecasting purposes, the assessment of rating curves at such ungauged sites would be quite troublesome. 
Overall, a "perfect" gauged river site should be first accessible, equipped with hydrometric sensors for flow depth monitoring and suitable for velocity measurements that, in addition, should be carried out also for higher stages. However, this configuration is seldom feasible and for most of gauged river sites two different scenarios of data availability can be identified.

In the first one the gauged river site is equipped both for recording stage and for carrying out velocity measurements. However, although velocity data are available, often they refer to low flow due to the real difficulty to sample velocity points in the flow area during high floods. As a consequence, the rating curve above the field of the available velocity measurements might be unreliable, due to its extrapolation which might be affected by a significant level of uncertainty (Di Baldassarre and Montanari, 2009). In addition, if unsteady flow effects occur, the rating curve is not a one-toone relationship anymore (Herschy, 1985), thus producing a loop whose amplitude depends on how much the inertial and pressure forces can influence the flood propagation process (Moramarco et al., 2008).

In the second scenario, only stages are recorded at gauged site and no flow velocity measurements are available. In this case, the local discharge hydrograph can be assessed starting from observed stages by applying methods based on the Jones formula (Henderson, 1966) and its refinements (Fenton, 1999; Perumal et al., 2004). The uncertainty in the parameters estimation, as the celerity and the diffusivity, and/or the presence of unsteady flow, might make these methods less accurate for particular flood conditions (Perumal and Moramarco, 2005).

Therefore, the accuracy of the discharge assessment at gauged river site depends, on the one hand, on the velocity data availability for high stages and, on the other hand, on the reliability of the model to turn recorded stages into discharge hydrographs.

As far as the velocity measurements for high stages are concerned, they can be addressed by sampling the maximum flow velocity, which is located in the upper portion of the flow area, wherein velocity points can be easily sampled also during high flow conditions (Chiu, 1987). Indeed, many studies have shown that the two-dimensional velocity distribution and, hence, the mean flow velocity can be obtained starting from the maximum flow velocity, such as proposed by Chiu $(1987,1988)$ who derived the probability distribution function of velocity through the entropy theory (Shannon, 1948). This insight, i.e. to monitor the river discharge by sampling the maximum flow velocity only, is of great interest for hydrological practices, also because new radar technologies are now available to measure the surface flow velocity, which often coincides with the maximum flow velocity (Plant et al., 2005; Costa et al., 2006; Fulton and Ostrowski, 2008).

Moreover, considering that continuous water level observations are straightforward to obtain and cheap, a great support in the continuous discharge estimation can be achieved by coupling the information coming from both water level and occasional surface velocity measurements.

Discharge estimation using the methods based on hydraulic routing of the recorded flood stage hydrograph can be considered as a more robust and reliable tool than the other methods currently in vogue. However, the lack of topographical data of river cross-sections along with the issue of the Manning's roughness coefficient calibration and often inhibits the use of hydraulic models.

Indeed, the choice of the "correct" Manning's roughness coefficient is a challenge for hydraulic modellers (Papperberger et al., 2005), in spite of the availability of several criteria concerning the selection of the value (Chow et al., 1988). The easiest way is to relate the Manning's roughness coefficient to the physical characteristics of river channel (bed material, irregularity, vegetation, etc. ...) and to select the suitable value from tables (Chow et al., 1988), formulae (Cowan, 1956) or photographs (Barnes, 1967). Unfortunately the Manning's roughness coefficient, being a parameter, is depending also on the numerical scheme of hydraulic model and on the approximations concerning the modelling channel geometry and hydraulic structures (Papperberger et al., 2005; Beven and Carling, 1992). Therefore for a gauged site, the solution is to calibrate the Manning's roughness coefficient using velocity measurements, such as recommended in the manuals of hydraulic packages (DHI, 2001; US Army Corps of Engineers, 2008). Specifically the calibration is performed for each velocity measurement by assigning the observed discharge and minimizing the error in simulating stage and/or mean flow velocity (Moramarco and Singh, 2010). A robust sample of discharge measurements is, however, needed to take into account the effects of roughness variations with the stage or the seasonality.

Therefore, the aim of this work is to address the discharge assessment at a gauged river site wherein the data availability is limited to observed water levels. In this contest, a procedure that estimates the discharge hydrograph, in near real time, starting from the observed stage and occasional surface flow velocity measurements is proposed. The procedure is based on the application of a hydraulic model to route the recorded stage and a velocity distribution model to assess the instantaneous discharge which is used, in turn, for the Manning's roughness coefficient calibration in the hydraulic model.

To this end, the hydraulic model developed by Arico et al. $(2009,2010)$ and based on the MAST numerical technique (Noto and Tucciarelli, 2001; Nasello and Tucciarelli, 2005), is applied. The model has already been applied in river reaches for which concurrent stages are recorded at both ends (Arico et al., 2009). The use of the hydraulic model involves, however, the two previous issues concerning the cross-section data availability and the Manning's roughness coefficient calibration, both addressed in this study. In particular, for the first one, the minimum channel length 
downstream of the gauged site is identified by investigating the length necessary to make negligible the effects of the downstream boundary condition on discharge assessment at the upstream end. The positive impact of this analysis consists to drastically reduce the number of topographic river cross-sections, with a great benefit in terms of data acquisition costs. For the second issue, the calibration of Manning's roughness coefficient is addressed by turning occasional surface flow velocity measurements into instantaneous discharge values through the simplified formulation of Chiu's velocity distribution model, such as proposed by Moramarco et al. (2004).

Flood events observed in three gauged river sites along the Tiber River are used for the analysis.

The paper is thus organized as follows: Sect. 1 describes the theoretical background of the hydraulic model applied for routing the stages recorded at gauged site. Section 2 provides an overview of the velocity distribution model used for estimating the instantaneous discharge from the occasional surface velocity measurements. Section 3 focuses the criterion to initially evaluate the minimum extension of the modelled river reach downstream the gauged section. Section 4 describes the methodology to turning the recorded stages into discharge hydrograph, along with the procedure of the Manning's roughness calibration. Section 5 presents the performance criteria adopted for the analysis, while Sect. 6 shows results of the proposed procedure for the three gauged river sections along the Tiber River. Finally, conclusions are drawn in the last section.

\section{The hydraulic model}

Unsteady flow in natural channels can be described by the Saint-Venant equations (De Saint-Venant, 1871). Assuming that the flow varies gradually, the governing equations can be written, neglecting the inertial terms and the lateral inflow, in the following diffusive form:

$$
\begin{aligned}
& \frac{\partial A}{\partial t}+\frac{\partial q}{\partial x}=0 \\
& \frac{\partial H}{\partial x}=-\frac{n^{2} q|q|}{A^{2} R^{4 / 3}}
\end{aligned}
$$

where $H, A, R, n$ and $q$ are, respectively, water surface level, cross-section flow area, hydraulic radius, Manning's roughness coefficient and discharge; $x$ and $t$ represent the distance along the channel and the time, respectively. The two first order equations, Eqs. (1) and (2), can be merged into one second order equation having $H$ as unknown, that is:

$$
\frac{\partial H}{\partial t}-\frac{1}{T} \frac{\partial}{\partial x}\left(\frac{R^{2 / 3} A}{n} \frac{\nabla_{x} H}{\sqrt{\left|\nabla_{x} H\right|}}\right)=0
$$

where $T$ is the section width, and $\nabla_{x}$ is the spatial gradient operator along the direction $x$ :

$\nabla_{x}=\frac{\partial}{\partial x}$

For this analysis, the upstream boundary condition is given by the recorded stages, $h_{r e c}(t)$ :

$h(0, t)=h_{\text {rec }}(t)$

while at the downstream end, two different types of boundaries are considered:

(1) the kinematic assumption:

$\left.\nabla_{x} H\right|_{x=L}=-S_{0}$

and (2) the zero diffusion assumption:

$\left.\frac{\partial^{2} H}{\partial x^{2}}\right|_{x=L}=0$

with $L$ being the channel length and $S_{0}$ the bed slope.

The Eq. (3) is numerically solved using the MAST approach (Noto and Tucciarelli, 2001; Tucciarelli and Termini, 2000), as better described in Appendix A.

Previous numerical and laboratory experiments (Aricò et al., 2009, 2010) have proved that, if the downstream channel section of the computational domain is far enough from the upstream one, the downstream boundary condition can be replaced with an approximated boundary without any significant effect on the discharge computed at the upstream site.

It is worth noting that the choice of minimum channel length, which is inferred here through synthetic numerical tests, as shown in the Sect. 3, has great impact in terms of overall cost linked to topographic surveys of river crosssections downstream the gauged site.

\section{The flow velocity distribution model}

The critical point of the application of the hydraulic model is the calibration of the Manning's roughness coefficient. This issue is addressed in this study by exploiting occasional surface flow velocity measurements, through which the instantaneous discharge is assessed and used as benchmark for the calibration of the hydraulic model. The theoretical basis of discharge estimation using surface flow velocity can be traced back to the maximum entropy principle (Jaynes, 1957). This principle is used as statistical inference to solve a probability matter (Singh, 1986, 2011), for instance to select a probability distribution function, when the information available about the variable is limited to some average quantities, defined constraints, such as the mean, variance etc. In the framework of open channels, the pioneer of the application of entropy theory was Chiu $(1987,1989)$, who predicted the two-dimensional flow velocity distribution as a 
function of maximum flow velocity, $u_{\max }$, and curvilinear coordinates in the physical space. We refer to Appendix B for more details. However, for practical applications Chiu's velocity distribution is sometime complex to apply even for the parameters estimation (Chiu and Said, 1995; Moramarco et al., 2004). For that, Moramarco et al. (2004) reduced Chiu's model complexity by assuming that the velocity distribution written for the vertical where $u_{\max }$ occurs, hereafter named $\mathrm{y}$-axis, can be applied to other verticals in the following form:

$$
\begin{aligned}
u\left(x_{\mathrm{v}}, y\right)= & \frac{u_{\max }\left(x_{\mathrm{v}}\right)}{M} \ln \left(1+\left(e^{M}-1\right) .\right. \\
& \left.\frac{D\left(x_{\mathrm{v}}\right)-y}{D\left(x_{\mathrm{V}}\right)-h_{u}} \exp \left(1-\frac{D\left(x_{\mathrm{V}}\right)-y}{D\left(x_{\mathrm{V}}\right)-h_{u}}\right)\right)
\end{aligned}
$$

where $x_{\mathrm{v}}$ is the position of the vertical with respect to the $y$ axis $\left(x_{\mathrm{V}}=0\right), y$ the depth of the velocity point location along the vertical and $u\left(x_{\mathrm{v}}, y\right)$ is the horizontal velocity; $D\left(x_{\mathrm{v}}\right)$ and $u_{\max }\left(x_{\mathrm{v}}\right)$ are the water depth and the maximum velocity sampled along the vertical (Herschy, 1985), respectively; $h_{u}$ is the depth below the water surface where $u_{\max }(0)$ (hereafter $u_{\max }$ ) occurs ( $h_{u}=0$ if $u_{\max }$ occurs at the surface). $M$ is the entropy parameter, which is a characteristic of the river cross section (Moramarco and Singh, 2010) and can be calibrated using historical data of velocity measurements (see Appendix B).

Therefore, by sampling $u_{\max }$ only and knowing the crosssection geometry, Chiu's velocity distribution allows the estimation of mean flow velocity and, hence, of discharge. In addition, in order to drastically reduce the time required for sampling, it is assumed that the maximum velocity $u_{\max }(x)$ along the generic vertical depends on the maximum velocity value, $u_{\max }$, sampled at y-axis, through the following elliptical relationship (Moramarco et al., 2011):

$u_{\max }\left(x_{\mathrm{v}}\right)=u_{\max } \sqrt{1-\left(\frac{x_{\mathrm{v}}}{x_{\mathrm{s}}}\right)^{2}}$

where $x$ is the abscissa measured from the vertical where the maximum velocity $u_{\max }$ is sampled (y-axis) and $x_{\mathrm{s}}$ is the abscissa of the right or left sidewall. For narrow river sections, Eq. (7) should be modified by raising the power to 1 instead of 0.5 , thus obtaining for $u_{\max }\left(x_{\mathrm{V}}\right)$ a representation in terms of parabolic curve (Moramarco et al., 2011).

It is worth noting that, if $u_{\max }$ occurs on the water surface and $u_{\max S}=u_{\max }$, its sampling can be done by using an immovable and/or hand-held radar unit which makes possible a very quick measurement (Fulton and Ostrowski, 2008). This is of great interests in the framework of streamflow measurements because, even if $u_{\max }$ occurred below the water surface it would be estimated through Eq. (8) written for the y-axis:

$u_{\max }=\frac{u_{\max }}{\frac{1}{M} \ln \left[1+\left(e^{M}-1\right) \delta e^{1-\delta}\right]}$ where $\delta=\frac{D(0)}{D(0)-h_{u}}$ is a parameter easily assessable through the historical data of velocity measurements at the gauged site.

The reliability of the simplified velocity distribution model based on Eqs. (6) and (7) and hereafter named "entropy model", has been tested in gauged sites of different rivers providing satisfactory results for different flood conditions (Moramarco et al., 2007, 2011). A sketch of velocity distribution obtained by using the entropy model is in Fig. 1.

In short, the procedure for the instantaneous discharge assessment at a gauged site consists as follows:

1. sampling of $u_{\max }$ which gives information about $u_{\max }$ value using Eq. (8) and its location (y-axis) in the flow area;

2. knowning $u_{\max }$ value, the distribution of $u_{\max }(x)$ can be assessed by Eq. (7) for an assigned cross-section geometry;

3. two-dimensional flow velocity distribution can now be estimated by Eq. (6), from which mean flow velocity and, hence, instantaneous discharge can be assessed, by applying the velocity-area method (Herschy, 1985).

Therefore, based on the instantaneous discharge such as assessed by the entropy model, the calibration of the Manning's roughness coefficient can be addressed in hydraulic model following the procedure described in Sect. 4 .

\section{Proposed domain extension criterion}

The main advantage of using the hydraulic model for discharge estimation is that the effect of topographic error is averaged along the reach extension and the error in discharge estimation at upstream end, due to the approximation in the adopted downstream boundary condition, increases with decreasing domain extensions. However, to model a long reach, an expensive detailed survey of the river topography is needed. This implies the need for quantifying, through an objective criterion, the minimum length required to achieve negligible errors in the computed upstream discharge, due to the approximation embedded in the adopted downstream boundary condition.

The minimum domain extension required by the hydraulic model depends on both the real cross section geometry and the river morphology downstream of the upstream section but a preliminary estimation can be obtained as a function of the main features of the simulated event, according to the assumption of prismatic channel and constant bed slope. These features are the initial water depth inside the channel, the time derivative of flow depth at the gauged section, Manning's roughness coefficient and bed slope. If we also assume 


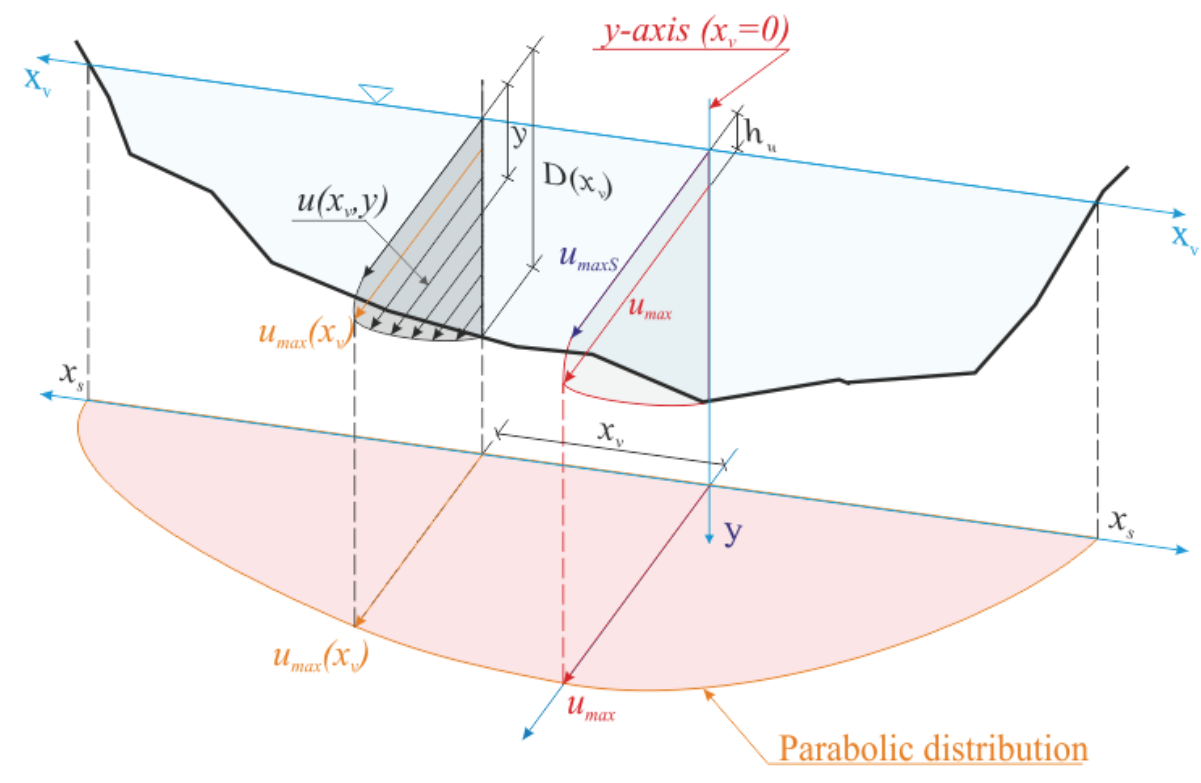

Fig. 1. Sketch of the 2-D velocity distribution $u\left(x_{\mathrm{V}}, y\right)$, in the hypothesis of parabolic distribution of maximum velocity, $u_{\mathrm{max}}\left(x_{\mathrm{V}}\right)$, across the river section. $x_{\mathrm{V}}$ position of the vertical with respect to the y-axis $\left(x_{\mathrm{V}}=0\right)$ wherein $u_{\max }$ occurs, $y$ depth of the velocity point along the vertical, $D\left(x_{\mathrm{V}}\right)$ and $u_{\max }\left(x_{\mathrm{V}}\right)$ water depth and maximum velocity along the vertical, $u_{\max } S$ surface velocity at y-axis, $h_{u}$ depth where $u_{\text {max }}$ occurs.

large rectangular section and negligible lateral flow, Eq. (3) can be written in the form:

$$
\frac{\partial H}{\partial t}-\frac{\partial}{\partial x}\left(\frac{h^{5 / 3}}{n} \frac{\nabla_{x} H}{\sqrt{\left|\nabla_{x} H\right|}}\right)=0
$$

wherein $H$ is surmised as

$H=-S_{0} x+h$

where $h$ is the flow depth and $S_{0}$ is the channel slope.

At the upstream end we assign a very simple boundary condition that can be easily derived from the known measured stage hydrograph. Specifically, at the upstream end a linear variation of water depth starting from an initial value $h_{0}$ is considered:

$h(0, t)=h_{0}+\left.\frac{\mathrm{d} h}{\mathrm{~d} t}\right|_{x=0} t$ with $\left.\frac{\mathrm{d} h}{\mathrm{~d} t}\right|_{x=0}=$ constant

At downstream end the kinematic assumption is taken:

$$
\left.\nabla_{x} H\right|_{x=L}=-S_{0}
$$

According to the upstream boundary condition given by Eq. (10a), the water surface gradient, $\left.\nabla_{x} H\right|_{x=0}$, will initially become more negative and then will increase asymptotically toward a finite value equal to the channel slope as shown in Fig. 2, wherein, by way of example, this quantity is plotted for two different channel lengths and assuming the same channel slope and Manning's roughness coefficient.
Because flow water depth in the upper section is known, the error in the upstream discharge computed from the solution of Eqs. (9) and (10) is due to the error in the water surface gradient computed in the same section. According to the very simple adopted scheme, this error is due only to the approximation of the downstream boundary conditions that affects the upstream error as much as short is the reach length. This implies that, using any possible downstream boundary condition, the exact solution is the one computed with a very large domain extension, that is for $L \rightarrow \infty$. The difference between the value of the longitudinal water surface gradient computed using a finite extension and the one assessed for $L \rightarrow \infty$ will initially rise up to a maximum value and then, after the minimum of the gradient is attained, will tend to zero (see Fig. 2).

In order to provide a general criterion for choosing the minimum channel length as much general as possible, the following dimensionless variables are considered:

$$
\left\{\begin{array}{l}
\eta=h / L \\
\lambda=x / L \\
\tau=\frac{t}{n L^{1 / 3}}
\end{array}\right.
$$

Equation (9) can be written in the following dimensionless form:

$$
\begin{aligned}
& \frac{\partial \eta}{\partial \tau}+\frac{\partial}{\partial \lambda}\left(\eta^{5 / 3} \frac{\nabla_{\lambda} \Psi}{\sqrt{\left|\nabla_{\lambda} \Psi\right|}}\right)=0 \\
& \Psi=-S_{0} \lambda+\eta \\
& \eta=\eta_{0}+\eta_{0}^{\prime} \tau \text { at } \lambda=0
\end{aligned}
$$




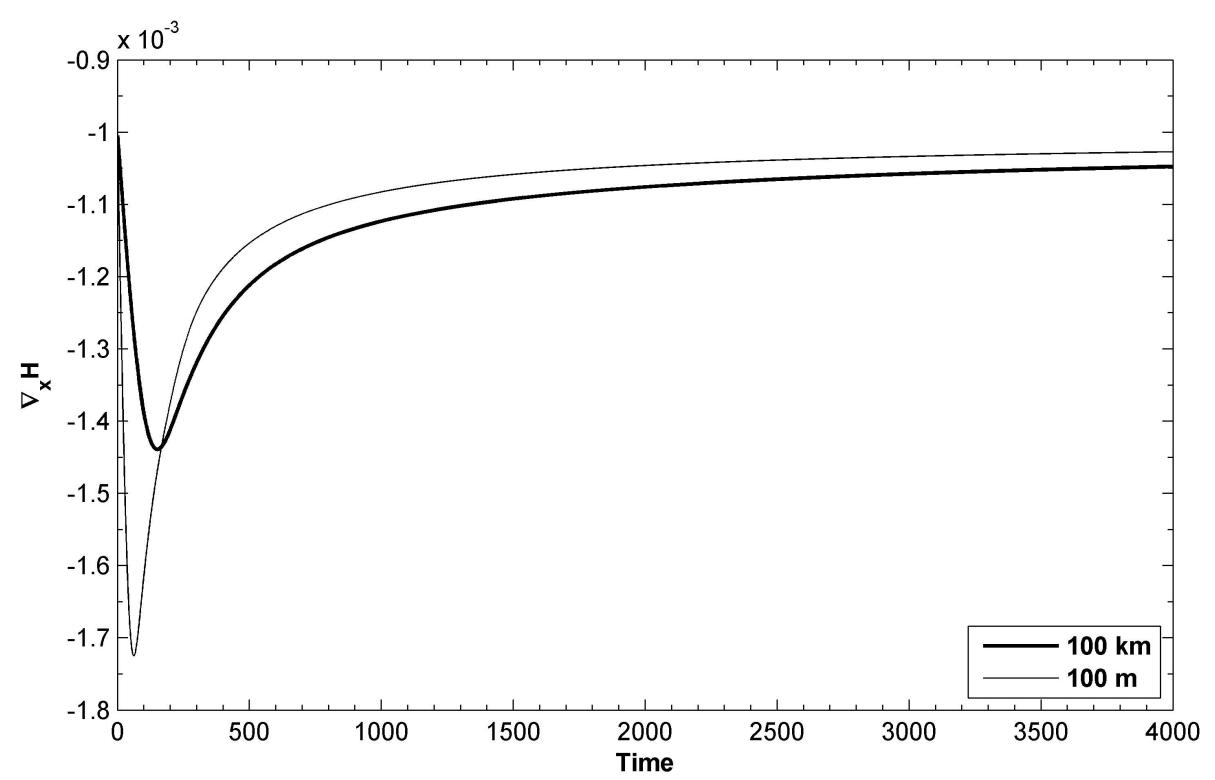

Fig. 2. Plot of longitudinal water surface gradient, $\nabla_{x} H$, versus time at $x=0$ for two channel lengths.

and the downstream boundary as:

$\nabla_{\lambda} \Psi=-S_{0}$ at $\lambda=1$

where

$$
\eta_{0}^{\prime}=\left.\frac{\partial \eta}{\partial \tau}\right|_{\lambda=0}
$$

At given point $(\lambda, \tau)$, observe that the solution $\eta$ of Eqs. (12)(13) depends on parameters $S_{0}$ (Eqs. 12b and 13b) and $\eta_{0}$ and $\eta_{0}^{\prime}$ (Eq. 13a). If we assume the most severe condition: $\eta_{0}=0$, the solution depends on the parameters $S_{0}$ and $\eta_{0}^{\prime}$ only. It is worth noting that parameter $\eta_{0}^{\prime}$ is a function of the Manning's roughness coefficient, $n$, as:

$\eta_{0}^{\prime}=\left.\frac{\mathrm{d} h}{\mathrm{~d} t}\right|_{x=0} \frac{n}{L^{2 / 3}}$

For any occurring upstream flow depth and Manning's roughness coefficient, the discharge estimation error is proportional to the error in the gradient root estimation (see Eq. 2). The maximum error, that is the maximum difference between the root of the gradient at $x=0$ computed with the actual domain length and the same root computed using an infinite length, turns out to be:

$$
\begin{aligned}
E & =\max _{t} \mid \sqrt{-\left.\nabla_{x} H\right|_{x=0}\left(n, \frac{\mathrm{d} h}{\mathrm{~d} t}, S_{0}, L, t\right)} \\
& -\lim _{L \rightarrow \infty} \sqrt{-\left.\nabla_{x} H\right|_{x=0}\left(n, \frac{\mathrm{d} h}{\mathrm{~d} t}, S_{0}, L, t\right)} \mid
\end{aligned}
$$

and in dimensionless form:

$$
\begin{array}{r}
E=\max _{\tau} \mid \sqrt{-\left.\nabla_{\lambda} \Psi\right|_{\lambda=0}\left(\eta_{0}^{\prime}, S_{0}, \tau\right)} \\
-\lim _{\eta_{0}^{\prime} \rightarrow 0} \sqrt{-\left.\nabla_{\lambda} \Psi\right|_{\lambda=0}\left(\eta_{0}^{\prime}, S_{0}, \tau\right)} \mid
\end{array}
$$

The limit in Eq. (15) can be simply computed using a very large value of $L$ instead of the domain extension used to compute the gradient in the same Eq. (15).

\section{Synthetic test and channel length selection}

A set of 120 synthetic tests have been done by varying channel length and bottom slope. The error $E$, computed through Eq. (16), is plotted in Fig. 3 as a function of the dimensionless variable $\eta_{0}^{\prime}$ and different $S_{0}$ values. As the limit in Eq. (15) is computed always for a finite value of $L$, the error $E$ attains the zero value for a $\eta_{0}^{\prime}$ value a bit greater than zero as shown in Fig. 3. Similar results have been obtained by changing the downstream boundary condition given by Eqs. (10b) or (13b) with the one referring to zero-diffusion (see Fig. 4):

$$
\begin{aligned}
& \frac{\partial^{2} H}{\partial x^{2}}=0 \\
& \text { or } \\
& \frac{\partial^{2} \Psi}{\partial \lambda^{2}}=0
\end{aligned}
$$

Based on the two above graphs the criterion for selecting the minimum channel length is proposed by assigning a threshold to the relative error in the peak discharge estimation. Indeed, it can be easily inferred from Eq. (2) that at upstream 


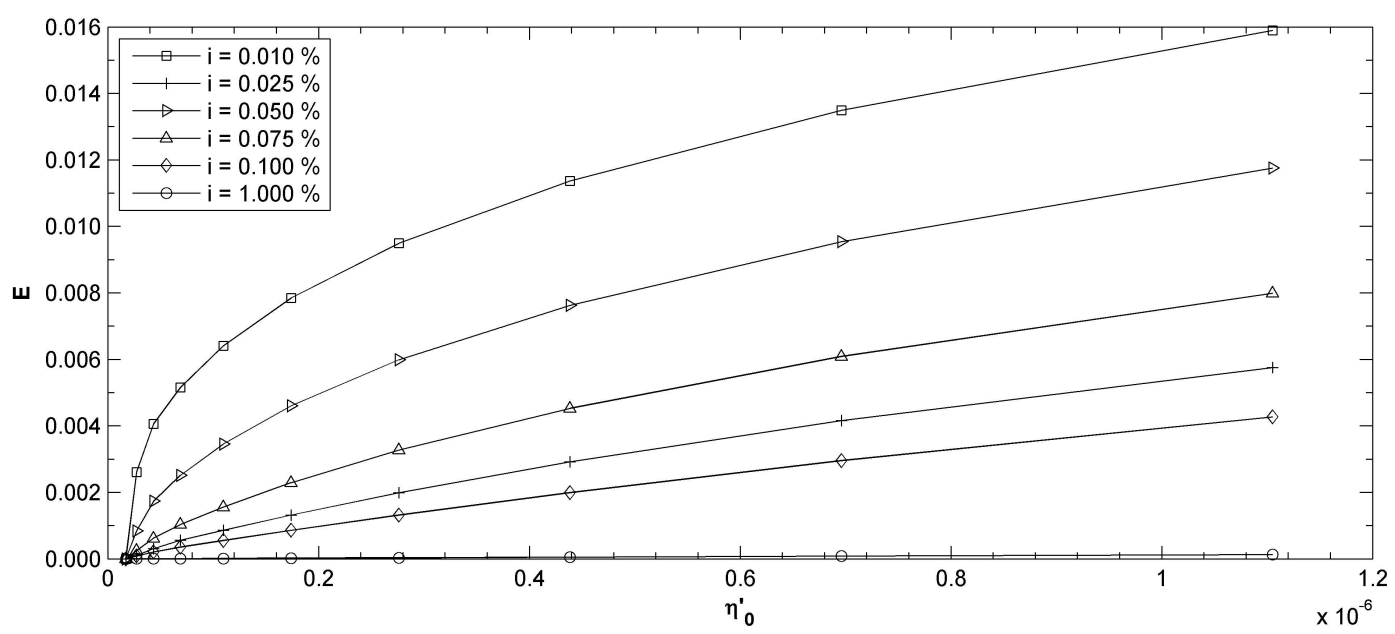

Fig. 3. Error in the root of water surface gradient computed using the boundary condition of Eq. (13b) versus the dimensionless quantity, $\eta_{0}^{\prime}$.

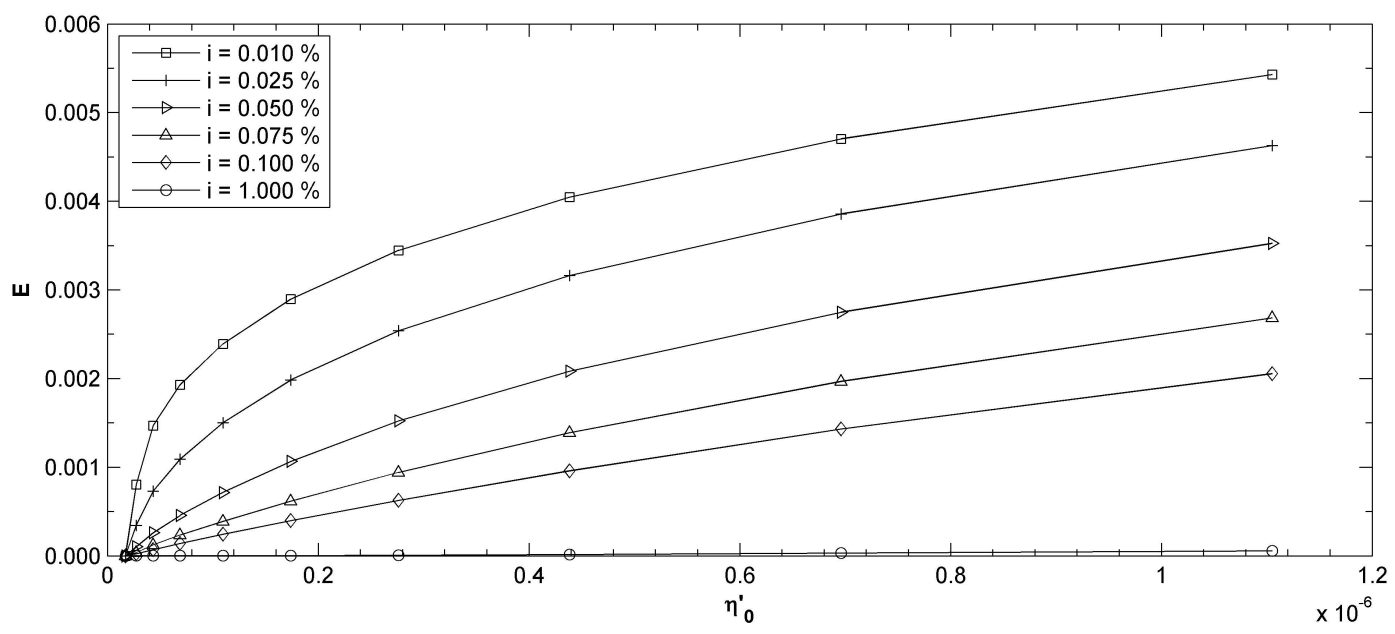

Fig. 4. As in Fig. 3, but for the downstream boundary condition given by Eq. (17b).

end, wherein the stage is recorded, the error of $q_{\max }$ is tied mainly to $\sqrt{\left|\nabla_{x} H_{\max }\right|}$ and $n$ only. Therefore, the relative error, $E_{\mathrm{d}}$, is expressed by:

$E_{\mathrm{d}}=\frac{\left|q_{\max }-q_{\max }^{\infty}\right|}{q_{\max }^{\infty}}=\frac{\left|\sqrt{\left|\nabla H_{\max }\right|}-\sqrt{\left|\nabla H_{\text {max }}^{\infty}\right|}\right|}{\sqrt{\left|\nabla H_{\max }^{\infty}\right|}} \leq \frac{E}{\sqrt{S_{0}}}$

where $\nabla H_{\max }$ and $\nabla H_{\max }^{\infty}$ are the water surface gradient corresponding to the maximum discharge computed according to the given reach length and to an infinite reach length, respectively; $E$ can be obtained by the graphs of Figs. 3 and 4 or directly by Eq. (15). The minimum length $L$ corresponding to a given threshold of $E_{\mathrm{d}}$ can be estimated according to the following procedure:

1. based on the assigned $E_{\mathrm{d}}$ threshold, the specific error $E$ can be estimated by Eq. (18) once channel slope is known;
2. through Fig. 3 or 4 the $\eta_{0}^{\prime}$ value corresponding to the estimated error $E$ and bed slope $S_{0}$, can be assessed;

3. finally, the minimum channel length $L$ can be computed according to Eq. (14) provided that $\left.\frac{\mathrm{d} h}{\mathrm{~d} t}\right|_{x=0}$ and $n$ are known.

As the downstream condition of zero-diffusion, Eq. (17b), always gives the minimum length, the graphs of Fig. 4 should be preferred.

By way of example, assuming $E_{\mathrm{d}}=0.05$ and the measured upstream water level hydrograph reaching the maximum rise of $1 \mathrm{~m}$ in $1 \mathrm{~h}$ in a channel with $S_{0}=4 \times 10^{-4}$ and $n=0.04 \mathrm{~m}^{-1 / 3} \mathrm{~s}$, we get:

$E=E_{\mathrm{d}} \sqrt{S_{0}}=0.001$ 
Based on Fig. 4, the dimensionless time derivative $\eta_{0}^{\prime}=$ $1.1 \times 10^{-7}$ is inferred. Then, the minimum length is compute by Eq. (14) obtaining:

$L=\left(\left.\frac{\mathrm{d} h}{\mathrm{~d} t}\right|_{x=0} \frac{n}{1.1 \times 10^{-7}}\right)^{3 / 2} \approx 1000$

The estimated error, $E$, is very sensitive to the bed slope. In the previous case, to achieve en error equal to 0.03 with a slope $S_{0}=10^{-4}$, we need a reach length of more than $10000 \mathrm{~m}$. A much smaller extension is required if the bed slope is of the order of $10^{-3}$. In this case, with a channel length of $1000 \mathrm{~m}$, we attain an error of only $0.7 \%$.

From a practical point of view, Eq. (18) and Figs. 3-4 should be used only to have an initial guess of the minimum channel length required to get an error $E_{\mathrm{d}}$ less than a fixed threshold. The sensitivity of the computed upstream discharge with respect to $L$, as well as the resulting error, have to be estimated using the same hydraulic model after the initial $L$ value is set and the corresponding topographic data are provided. If the sensitivity is not negligible, an extension of $L$ (and a consequent new topographic data acquisition) is in order.

\section{Discharge estimation procedure}

The procedure for estimating the discharge hydrograph starting from the recorded stages consists in the following steps.

1. Based on the slope of the river reach downstream the gauged river site, the minimum channel length is assessed setting a threshold $E_{\mathrm{d}}$, for instance 0.05 . The rising limb slope, $\left.\frac{\mathrm{d} h}{\mathrm{~d} t}\right|_{x=0}$, is assigned as the maximum of the historical recorded stages while an initial value of Manning's roughness coefficient is surmised.

2. The Manning's roughness coefficient is then calibrated by exploiting occasional velocity measurements along the rising limb of the observed stages. In particular, the instantaneous discharge is estimated through the entropy model which provides the two-dimensional velocity distribution and, hence, the discharge value, " $q_{\text {obs }}$ ", used as benchmark. Therefore, the Manning's roughness value is calibrated by minimizing the percentage error, $\varepsilon$, in the discharge, $q_{\text {comp }}$, computed by the hydraulic model at the time of the measurement, $t_{\text {meas }}$, as:

$$
\varepsilon=\frac{q_{\text {comp }}\left(t_{\text {meas }, n}\right)-q_{\text {obs }}\left(t_{\text {meas }}\right)}{q_{\text {obs }}\left(t_{\text {meas }}\right)} \times 100
$$

The Brent algorithm (Brent, 1973) is used to find the minimum of Eq. (20).
3. Once $n$ has been calibrated, the recorded stages can be turned into discharge hydrograph through the application of the hydraulic model. A refinement of the discharge hydrograph can be achieved carrying out more instantaneous velocity measurements along the rising limb.

It is worth noting that once that the surface velocity is turned into instantaneous discharge and the Manning's roughness coefficient is calibrated, the flood event is still growing and then, for the times after the surface velocity sampling, a realtime estimation of discharge hydrograph is done.

\section{Performance criteria}

The performances of the proposed discharge estimation procedure have been evaluated through the following two criteria:

1. Nash-Sutcliffe criterion (Nash and Sutcliffe, 1970):

$$
\mathrm{NS}_{q}=\left[1-\frac{\sum_{i=1, N}\left(q_{i}^{*}-q_{i}\right)^{2}}{\sum_{i=1, N}\left(q_{i}^{*}-\overline{q^{*}}\right)^{2}}\right]
$$

where $q_{i}^{*}$ is the $i$-th data of the benchmark discharge hydrographs, $q_{i}$ is the $i$-th data of the simulated discharge hydrographs and $\overline{q_{i}^{*}}$ is the average value of the benchmark discharge hydrographs.

2. Relative magnitude peak error:

$$
\Delta q_{\mathrm{p}}=\left[\frac{q_{\mathrm{p}}}{q_{\mathrm{pM}}}-1\right] \times 100
$$

where $q_{\mathrm{p}}$ is the peak value in the computed discharge hydrographs, while $q_{\mathrm{pM}}$ is the peak reference value.

\section{Field application}

The proposed procedure for estimating the discharge hydrograph starting from recorded stages and occasional surface velocity measurements has been applied to several flood events occurred along the Tiber River (Central Italy), and monitored at gauged sections of Pierantonio $\left(1800 \mathrm{~km}^{2}\right)$, Ponte Nuovo $\left(4100 \mathrm{~km}^{2}\right)$ and Monte Molino $\left(5270 \mathrm{~km}^{2}\right)$. For the three river sites a reliable rating curve is available. In addition, for the Tiber River including the three gauged sites detailed topographical surveys of cross-sections are also available.

At Pierantonio gauged section continuous water level measurements by an ultrasonic sensor and direct discharge measurements carried out by current meters are available. Six 
Table 1. Observed peak discharge, $q_{\mathrm{pM}}$, time to peak, $t_{\mathrm{ph}}$, observed peak stage, $h_{\mathrm{pM}}$, time derivative in flow depth, $h_{0}^{\prime} \mid \max$, for flood events at Pierantonio gauged site.

\begin{tabular}{lclllll}
\hline Event & $q_{\mathrm{pM}}\left[\mathrm{m}^{3} \mathrm{~s}^{-1}\right]$ & $t_{\mathrm{ph}}[\mathrm{h}]$ & $h_{\mathrm{pM}}[\mathrm{m}]$ & Duration $[\mathrm{h}]$ & $h_{0}^{\prime} \mid \max \left[\mathrm{m} \mathrm{s}^{-1}\right]$ & Notes \\
\hline December 1996 & 380.53 & 22.5 & 4.74 & 49.5 & $1.39 \times 10^{-4}$ & \\
April 1997 & 429.44 & 32.5 & 5.07 & 74.5 & $1.94 \times 10^{-4}$ & \\
November 1997 & 308.17 & 18.5 & 4.22 & 45 & $1.28 \times 10^{-4}$ & \\
February 1999 & 427.93 & 21.5 & 5.06 & 59.5 & $2.67 \times 10^{-4}$ & \\
December 2000 & 565.89 & 74.0 & 5.92 & 100 & $2.39 \times 10^{-4}$ & Flooding \\
November 2005 & 779.03 & 30.5 & 7.1 & 64 & $2.06 \times 10^{-4}$ & Flooding \\
\hline
\end{tabular}

Table 2. As Table 1, but for Ponte Nuovo gauged section.

\begin{tabular}{ccccrc}
\hline Event & $\begin{array}{c}q_{\mathrm{pM}} \\
{\left[\mathrm{m}^{3} \mathrm{~s}^{-1}\right]}\end{array}$ & $\begin{array}{c}t_{\mathrm{pq}} \\
{[\mathrm{h}]}\end{array}$ & $\begin{array}{c}h_{\mathrm{pM}} \\
{[\mathrm{m}]}\end{array}$ & $\begin{array}{c}\text { Duration } \\
{[\mathrm{h}]}\end{array}$ & $\begin{array}{c}h_{0}^{\prime} \mid \max \\
{\left[\mathrm{m} \mathrm{s}^{-1}\right]}\end{array}$ \\
\hline November 2005 & 1073.2 & 32.75 & 8.52 & 70 & $4.89 \times 10^{-4}$ \\
December 2005 & 804.23 & 82.16 & 7.33 & 115 & $2.83 \times 10^{-4}$ \\
December 2008 & 874.73 & 146 & 7.64 & 160 & $3.04 \times 10^{-4}$ \\
\hline
\end{tabular}

flood events, whose main characteristics are reported in Table 1 , have been analysed for the methodology testing. The available direct discharge measurements cover almost all the events flow range, except for December 2000 and November 2005, when the flood came in floodplains and velocities measurements could not be carried out for the highest water levels (Perumal et al., 2007). These events have been already used by Arico et al. (2009) and Perumal et al. (2007) to validate related discharge estimation methods.

The Ponte Nuovo gauged section is equipped with ultrasonic flow measurement system (Quantum, 2002), which allows for continuous measurements of both water levels and discharges. The flood events occurred in November and December 2005 along with December 2008 have been used for the analysis. The main flood events characteristics are summarized in Table 2.

The Monte Molino gauged section has been subject of experimental tests using "non-contact" devices for surface water velocity measurement since December 2008, when a fixed radar sensor Sommer RG24(TM) (Sommer, 2006) was installed. More recently, the hand-held radar Decatur SVR ${ }^{(\mathrm{TM})}$ (Decatur, 2005) was tested at the same site. These radar devices have a signal frequency of $24 \mathrm{GHz}$ with a flow velocity range between $0.3 \mathrm{~m} \mathrm{~s}^{-1}$ to $10 \mathrm{~m} \mathrm{~s}^{-1}$. In addition, continuous water level measurements, provided by an ultrasonic sensor, and direct discharge measurements carried out by current meters, are also available. The flood events occurred in January and December 2010, whose main characteristics are summarized in Table 3 , have been considered for the investigation.
Table 3. As Table 1, but for Monte Molino gauged section.

\begin{tabular}{crlccc}
\hline Event & $\begin{array}{c}q_{\mathrm{pM}} \\
{\left[\mathrm{m}^{3} \mathrm{~s}^{-1}\right]}\end{array}$ & $\begin{array}{c}t_{\mathrm{pq}} \\
{[\mathrm{h}]}\end{array}$ & $\begin{array}{c}h_{\mathrm{pM}} \\
{[\mathrm{m}]}\end{array}$ & $\begin{array}{c}\text { Duration } \\
{[\mathrm{h}]}\end{array}$ & $\begin{array}{c}\left.h_{0}^{\prime}\right|_{\max } \\
{\left[\mathrm{m} \mathrm{s}^{-1}\right]}\end{array}$ \\
\hline January 2010 & 1105.2 & 41.5 & 9.54 & 83.5 & $1.94 \times 10^{-4}$ \\
December 2010 & 995.1 & 35 & 8.91 & 192 & $1.78 \times 10^{-4}$ \\
\hline
\end{tabular}

\subsection{The optimal channel length}

With the aim to verify the reliability of outcomes of synthetic tests, the optimal channel length was computed for the river reach downstream of the three investigated gauged sections. In the present application the hydraulic model uses the zerodiffusion downstream boundary condition such as given by Eq. (17a). Surmising a maximum error, $E_{\mathrm{d}}$, equal to 0.05 for all gauged sections, the minimum channel length has been assessed, using the procedure described in Sect. 3. Results of the procedure are summarized in Table 4 along with reference quantities used for the computation of the minimum channel length downstream of the gauged sites.

For the Pierantonio gauged site, the maximum error $E$ based on Eq. (18) has been found 0.019 and $\eta_{0}^{\prime}$ equal to $10^{-6}$ has been inferred through the graph in Fig. 4. Finally, assuming a Manning's roughness coefficient $0.048 \mathrm{~s} \mathrm{~m}^{-1 / 3}$ (Aricò et al., 2009) and using the maximum slope in the rising limb of the recorded stages for the event of December 2000 (see Table 1), the minimum channel length $L_{\min }=45 \mathrm{~m}$, downstream the Pierantonio site, is estimated through Eq. (14).

Similarly, for Ponte Nuovo and Monte Molino sites, $L_{\text {min }}$ is found equal to $400 \mathrm{~m}$ and $140 \mathrm{~m}$, respectively, (see Table 4).

Because the river topography in the validation tests is already known, the consistency of the minimum channel length obtained for the three gauged river sites has been tested using the observed flood events and an "infinite" channel length equal to $20 \mathrm{~km}$. By way of example, for the Pierantonio site, Fig. 5 shows the relative discharge peak error, $E_{\mathrm{d}}$, obtained by comparing the observed peak discharges and the 
Table 4. Values of minimum channel length, $L_{\min }$, estimated by Eq. (14). For other symbols see text.

\begin{tabular}{lccccccc}
\hline Gauged River site & $S_{0}$ & $E_{\mathrm{d}}$ & $E$ & $\eta_{0}^{\prime}$ & $n\left[\mathrm{~s} \mathrm{~m}^{-1 / 3}\right]$ & $\max \left(\left.h_{0}^{\prime}\right|_{\max }\right)\left[\mathrm{m} \mathrm{s}^{-1}\right]$ & $L_{\min }[\mathrm{m}]$ \\
\hline Pierantonio & $1.6 \times 10^{-3}$ & 0.05 & 0.0019 & $10^{-6}$ & 0.048 & $2.39 \times 10^{-4}$ & 45 \\
Ponte Nuovo & $0.85 \times 10^{-3}$ & 0.05 & 0.0015 & $3.6 \times 10^{-7}$ & 0.042 & $4.89 \times 10^{-4}$ & 400 \\
Monte Molino & $0.97 \times 10^{-3}$ & 0.05 & 0.0014 & $3 \times 10^{-7}$ & 0.042 & $1.94 \times 10^{-4}$ & 140 \\
\hline
\end{tabular}

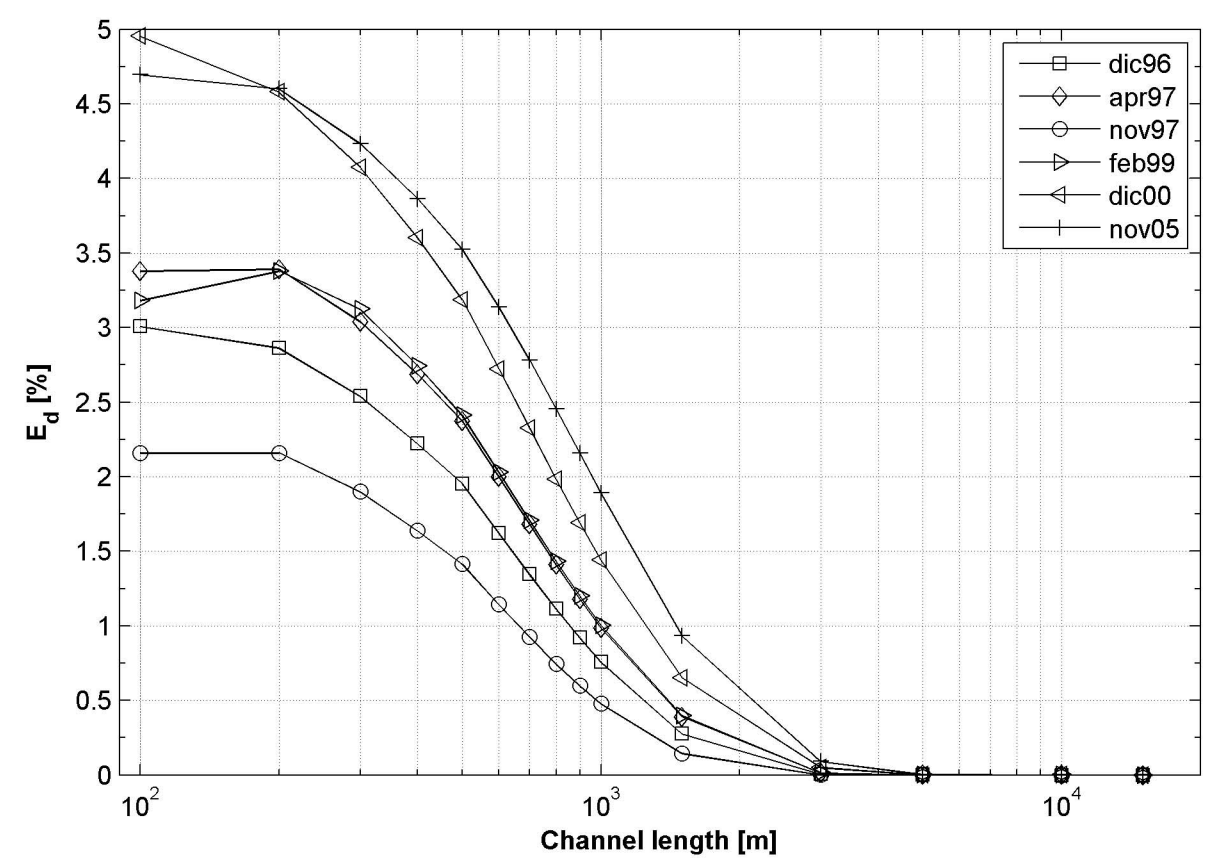

Fig. 5. Pierantonio gauged site: relative errors in peak discharge, $E_{\mathrm{d}}$, versus channel length for investigated events.

ones computed by the hydraulic model assuming different domain lengths, as well as the bed slope and the Manning's roughness coefficient reported in Table 4. As shown in Fig. 5, the error $E_{\mathrm{d}}$ is less than $5.5 \%$ for all events and greater than $5 \%$ only for events of December 2000 and November 2005, when flooding occurred.

Similar results have been obtained for the two other river sites. The minimum channel length has been first assessed and tested at the three gauged river sites, and afterwards the same has been applied in the Manning's roughness coefficient calibration procedure, as depicted in Sect. 4.

\subsection{Discharge hydrograph assessment}

The analysis presented here is of great interest for the hydrologic community because, in addition to addressing discharge monitoring during high floods by coupling the hydraulic model and the entropy one, it will reduce the time required for flow velocity measurement, so that the discharge can be monitored in different gauged sites for the same flood. Indeed, the entropy model, by exploiting the instantaneous velocity measurements (for instance by hand-held radar sensor), can provide the instantaneous discharge value to be used for Manning's roughness calibration. It has to be pointed out that for Pierantonio and Ponte Nuovo gauged site, since surface velocity measurements were not available there, they have been mimicked at Pierantonio by using site the instantaneous discharges obtained by converting the corresponding recorded stage through the rating curve, and at Ponte Nuovo by using the measured discharges given by the ultrasonic flowmeter.

\subsubsection{Pierantonio gauged site}

The calibration of the Manning's roughness coefficient has been carried out at different times along the rising limb of discharge hydrographs. Related performances have been computed and summarized in Table 5, for different hypothetical sampling times along the rising limb.

The comparison between the observed discharge hydrographs and the ones computed by the proposed method using the estimated $L_{\min }=45 \mathrm{~m}$, is shown in Fig. 6. It can be 

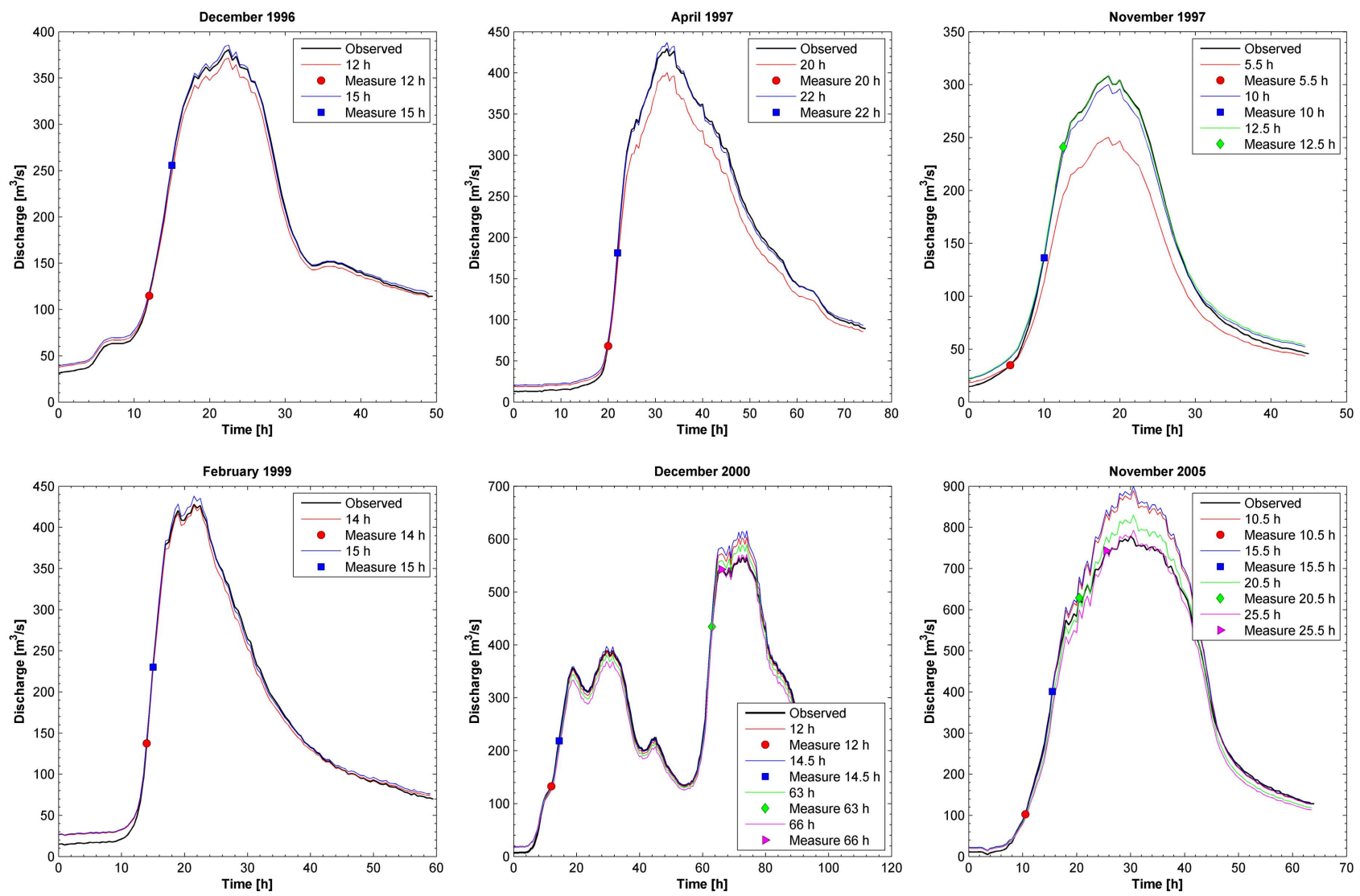

Fig. 6. Comparison between the observed and calibrated discharge hydrographs at the Pierantonio using $L_{\min }=45 \mathrm{~m}$.
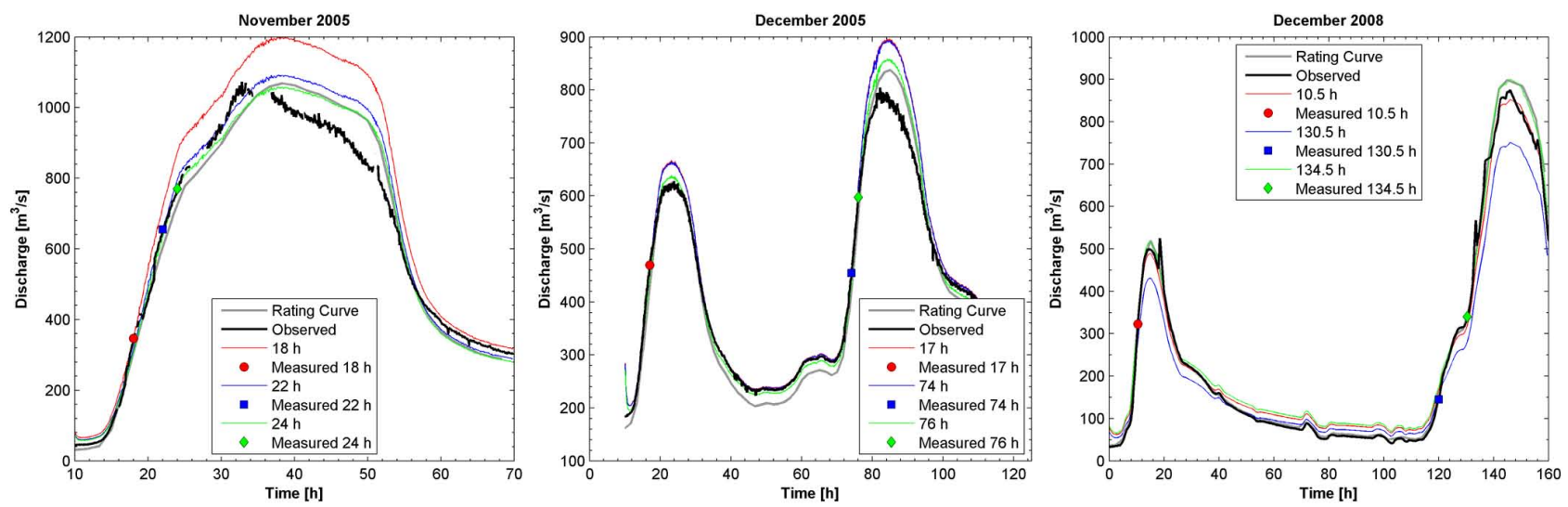

Fig. 7. Comparison between the observed and computed discharge hydrograph at Ponte Nuovo site using a $400 \mathrm{~m}$ channel.

seen, for all investigated events, a good match is obtained when the calibration is carried out in the middle zone of rising limb, when the flood is still evolving. For the event of December 2000, the maximum error in peak discharge estimation did not exceed $9 \%$, even though the surface velocity measurements were made for the first rising limb and at the beginning of the second rising limb of the event as inferred from Table 5 and Fig. 6 . It is worth noting that the optimum Manning's roughness coefficient, calibrated during the rising limb of the event December 1996, is very close to the optimum one obtained for all other events except for November 2005, see Table 5, whose peak discharge value was about twice the one of December 1996. 

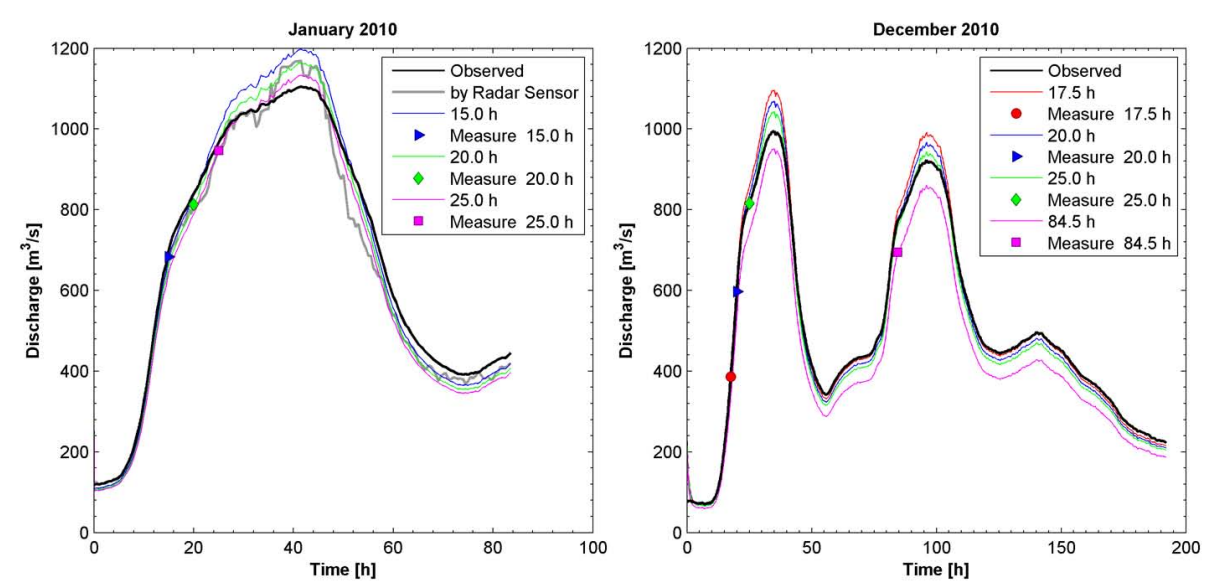

Fig. 8. Comparison between the observed and computed discharge hydrograph at Monte Molino site using as channel length $140 \mathrm{~m}$.

Table 5. Performance analysis in terms of error in peak discharge, $\Delta q_{\mathrm{pM}}$, and Nash-Sutcliffe, $\mathrm{NS}_{q}$, for investigated events at Pierantonio gauged site. The calibrated Manning's roughness coefficient is also shown.

\begin{tabular}{llcrc}
\hline Event & $\begin{array}{c}\text { Calibration } \\
\text { time }[\mathrm{h}]\end{array}$ & $\begin{array}{c}n \\
{\left[\mathrm{~s} \mathrm{~m}^{-1 / 3}\right]}\end{array}$ & $\begin{array}{c}\Delta q_{\mathrm{pM}} \\
{[\%]}\end{array}$ & $\begin{array}{c}\mathrm{NS}_{q} \\
{[\%]}\end{array}$ \\
\hline December & 12 & 0.0481 & -2.38 & 0.990 \\
1996 & 15 & 0.0464 & 1.33 & 0.999 \\
& 20 & 0.0513 & -6.77 & 0.957 \\
\hline April & 22 & 0.0470 & 1.73 & 0.998 \\
1997 & 28 & 0.0470 & 1.62 & 0.998 \\
\hline November & 5.5 & 0.0570 & -18.87 & 0.817 \\
1997 & 10 & 0.0475 & -2.67 & 0.995 \\
& 12.5 & 0.0462 & 0.05 & 0.998 \\
\hline February & 14 & 0.0480 & -0.46 & 0.994 \\
1999 & 15 & 0.0468 & 2.32 & 0.997 \\
\hline December & 12 & 0.0473 & 6.65 & 0.990 \\
2000 & 14.5 & 0.0463 & 8.81 & 0.982 \\
& 63 & 0.0483 & 4.24 & 0.987 \\
\hline November & 10.5 & 0.0487 & 14.14 & 0.932 \\
2005 & 15.5 & 0.0481 & 15.51 & 0.915 \\
& 20.5 & 0.0522 & 6.57 & 0.987 \\
& 25.5 & 0.0546 & 1.80 & 0.990 \\
\hline
\end{tabular}

\subsubsection{Ponte Nuovo gauged section}

As underlined above, the discharge at Ponte Nuovo site is monitored through an ultrasonic flowmeter station. Figure 7 shows the comparison between the discharge hydrographs recorded by the ultrasonic flowmeter and the ones computed through the proposed method. The performances of calibration and related Manning's roughness coefficients are shown
Table 6. As Table 5, but for Ponte Nuovo gauged site.

\begin{tabular}{llccc}
\hline Event & $\begin{array}{c}\text { Calibration } \\
\text { time }[\mathrm{h}]\end{array}$ & $\begin{array}{c}n \\
{\left[\mathrm{~s} \mathrm{~m}^{-1 / 3}\right]}\end{array}$ & $\begin{array}{c}\Delta q_{\mathrm{pM}} \\
{[\%]}\end{array}$ & $\begin{array}{c}\mathrm{NS}_{q} \\
{[\%]}\end{array}$ \\
\hline November & 18 & 0.0401 & 11.73 & 0.61 \\
2005 & 22 & 0.0440 & 1.86 & 0.88 \\
& 24 & 0.0454 & -1.36 & 0.92 \\
\hline December & 17 & 0.0394 & 11.84 & 0.94 \\
2005 & 74 & 0.0397 & 10.75 & 0.95 \\
& 76 & 0.0413 & 6.65 & 0.98 \\
\hline December & 10.5 & 0.0454 & -2.77 & 0.99 \\
2008 & 130.5 & 0.0429 & 2.78 & 0.98 \\
& 134.5 & 0.0426 & 3.5 & 0.98 \\
\hline
\end{tabular}

in Table 6. As in the previous study case, by calibrating in the middle part of rising limb the method satisfactorily reproduces the discharge hydrograph measured through the ultrasonic flow-meter, as shown in Fig. 7. In spite of the overbank flooding, which adds to the complexity of the three events, there are only large discrepancies in the upper part of recession limb, showing that there is a fair match between the estimated and observed discharge hydrographs. This is confirmed by the performance measures with the error in peak discharge less than $12 \%$ for all calibration times (see Table 6).

\subsubsection{Monte Molino gauged section}

At Monte Molino river site "non-contact" measurements of the maximum surface flow velocity measurements, $u_{\operatorname{maxS}}$, carried out by radar sensor along the y-axis are available. In order to estimate $u_{\max }$ from the measurement of $u_{\operatorname{maxS}}$, Eq. (8) has been used. The parameter $M$ and $\delta$ have been estimated on the basis of available historical velocity 
Table 7. Comparison between discharge computed by entropy model, $Q_{\text {ent }}$, and the observed one, $Q_{\text {obs }}$. Surface velocity, $u_{\text {maxS }}$, maximum velocity, $u_{\max }$, and radar device used for sampling are also tabled.

\begin{tabular}{|c|c|c|c|c|c|c|}
\hline Event & time [h] & Radar device & $u_{\operatorname{maxS}}\left[\mathrm{m} \mathrm{s}^{-1}\right]$ & $u_{\max }\left[\mathrm{m} \mathrm{s}^{-1}\right]$ & $Q_{\text {ent }}\left[\mathrm{m}^{3} \mathrm{~s}^{-1}\right]$ & $Q_{\text {obs }}\left[\mathrm{m}^{3} \mathrm{~s}^{-1}\right]$ \\
\hline \multirow{3}{*}{ January 2010} & 15 & \multirow{3}{*}{ Sommer RG-24(TM) } & 3.25 & 3.32 & 682.6 & 701.7 \\
\hline & 20 & & 3.36 & 3.43 & 812.1 & 839.7 \\
\hline & 25.5 & & 3.29 & 3.36 & 952.8 & 977.6 \\
\hline December 2010 & 84.5 & Decatur SVR ${ }^{(\mathrm{TM})}$ & 3.08 & 3.15 & 694.1 & 773.4 \\
\hline
\end{tabular}

measurements data and values of 1.77 and 1.33 have been found, respectively. Therefore, once $u_{\max }$ has been assessed, by applying Eq. (6) coupled with Eq. (7) written for a parabolic distribution of $u_{\max }\left(x_{\mathrm{v}}\right)$ across the flow area, the instantaneous two-dimensional velocity distribution and, hence, the discharge have been computed. Figure 8 shows for the events of January and December 2010, the comparison between the observed discharge hydrographs and the computed ones through the proposed procedure and, as it can be seen, a good match is found. Table 7 shows, besides the flow velocity quantities, the comparison between the instantaneous discharge computed by the entropy model and the observed ones for the investigated flood events. The Manning's roughness values calibrated through the instantaneous measurements and the performance measures of the procedure are shown in Table 8. For the event of January 2010 the calibration discharge was computed by using surface water velocities measured by the Sommer sensor. Unfortunately, this sensor was out of order during the event of December 2010; nevertheless, instantaneous water surface velocity measurements by means of hand-held Decatur $\mathrm{SVR}^{(\mathrm{TM})}$ radar were available. Once the Manning's roughness coefficient was calibrated, the hydraulic model has been able to satisfactory reproduce the observed discharge as shown in Fig. 8. It is worth noting that for December 2010 event, although the entropy model provided an error of about $10 \%$ on the instantaneous discharge computation (see Table 7), the hydraulic model was able to reconstruct satisfactory the event with an error on the first and second peak that did not exceed $4 \%$ and $7 \%$, respectively.

\section{Conclusions}

Based on the obtained results, the following conclusions can be drawn:

- The analysis of downstream boundary condition effects over the upstream discharge hydrograph computation has shown that short channel lengths are enough to achieve good performance of the diffusive hydraulic model, thus allowing a drastic reduction of the required topographical data of river cross-sections. This insight,
Table 8. As Table 5, but for Monte Molino gauged site. Radar devices used for surface flow velocity sampling are also reported.

\begin{tabular}{lllcrc}
\hline Event & $\begin{array}{l}\text { Calibration } \\
\text { time }[\mathrm{h}]\end{array}$ & $\begin{array}{l}\text { Radar } \\
\text { device }\end{array}$ & $\begin{array}{c}n \\
{\left[\mathrm{~s} \mathrm{~m}^{-1 / 3}\right]}\end{array}$ & $\begin{array}{r}\Delta q_{\mathrm{pM}} \\
{[\%]}\end{array}$ & $\begin{array}{c}\mathrm{NS}_{q} \\
{[\%]}\end{array}$ \\
\hline January & 15 & Sommer & 0.044 & 6.24 & 0.98 \\
2010 & 20 & RG-24(TM) & 0.045 & 3.80 & 0.98 \\
& 25.5 & & 0.046 & 0.98 & 0.97 \\
\hline December & 17.5 & - & 0.041 & 10.64 & 0.98 \\
2010 & 20 & - & 0.042 & 7.78 & 0.99 \\
& 25.5 & - & 0.043 & 4.86 & 0.99 \\
& 84.5 & Decatur & 0.047 & -3.95 & 0.94 \\
& & SVR & \\
& & & & & \\
\hline
\end{tabular}

however, needs to be further validated in the case of significant irregular sections, with respect also to the approximation adopted for the downstream boundary condition.

- The coupling of the hydraulic model with the velocity distribution model turned out to be useful for an accurate calibration of the Manning's roughness coefficient, allowing us to achieve high performance of the hydraulic model just considering the observed water levels and occasional measurements of surface flow velocity. Considering that the reliability of the procedure is mainly based on the Nash-Sutcliffe performance index, an uncertainty analysis will be addressed in future works to further support the findings.

- The developed algorithm can be conveniently adopted for the rating curve assessment at ungauged sites where only stages are recorded and the standard techniques for velocity measurements fail, in particular during high floods. In this case it is enough to sample the maximum surface velocity during the first part of the rising limb to achieve reliable estimates of discharge.

- Based on the proposed procedure, discharge hydrographs can be assessed in near real-time for whatever flood condition. This is of great support for flow velocity monitoring because, on the one hand, the sampling 
time are drastically reduced and operators can work in safe environment even during high floods, on the other hand, through the proposed procedure it will be possible to carry out velocity measurements by hand-held radar sensors for the same flood event in different river sites. Such a monitoring activity that can never be realized using the standard techniques of flow velocity measurements.

- Finally, the procedure can be considered for applications even in the framework of streamflow monitoring from satellite, considering that many current projects aim to exploit the possibility.

\section{Appendix A}

\section{Mast numerical solution}

Equation (3) is numerically solved in space and time using the MAST technique. The basic idea of the MAST algorithm is to apply a fractional time step procedure to compute the unknown surface level $H$ at time level $k+1$, when the surface level is known at time level $k$. In the first half-step the predicted level $H^{k+1 / 2}$ is estimated by integrating in time and space the following prediction equation:

$$
\frac{\partial H^{k+1 / 2}}{\partial t}-\frac{1}{T} \frac{\partial}{\partial x}\left(\frac{R^{2 / 3} A}{n} \frac{\nabla_{x} H^{k}}{\sqrt{\left|\nabla_{x} H^{k}\right|}}\right)=0
$$

In the second half-step the corrected level $H^{k+1}$ is obtained by solving the fully implicit discretization of the following correction equation:

$$
\frac{\partial H^{k+1}}{\partial t}-\frac{1}{\bar{T}} \frac{\partial}{\partial x}\left(\frac{\overline{R^{2 / 3} A}}{n}\left(\frac{\nabla_{x} H^{k+1}-\nabla_{x} H^{k}}{\sqrt{\left|\nabla_{x} H^{k}\right|}}\right)\right)=0
$$

where the top bar is the symbol of the mean (in time) operator, applied along the prediction step. The advantage of splitting the original problem in a prediction plus a correction problem is that these problems are much easier to solve than the original one.

By applying functional analysis, it can be shown that Eq. (A1) is convective and its solution depends on one upstream boundary condition only. After spatial integration, Eq. (A1) turns in a system of ordinary differential equations (ODEs). If a further approximation is made and the flux leaving from each computational cell along the time step is approximated with its mean (in time) value, the ODEs can be solved sequentially one after the other moving from the cells with higher to the cells with lower water level.

The corrective Eq. (A2) is diffusive and its solution depends on both the boundary conditions. After spatial discretization, a fully implicit time discretization is applied to the resulting system. The advantage of solving Eq. (A2) instead of Eq. (3) is that the unknown $H^{k+1}$ can be replaced by the unknown $\eta=H^{k+1}-H^{k+1 / 2}$. The new variable is small, along with its fluxes, with respect to $H^{k+1}$. This implies that also the error associated to the fully implicit numerical solution is small with respect to the error in the estimation of the original $H^{k+1}$ unknown. More details on the numerical solution computed using the MAST approach can be found in Nasello and Tucciarelli (2005).

\section{Appendix B}

\section{The Chiu's two-dimensional velocity model}

We have pointed out that in the framework of open channels, the pioneer of the application of the maximum entropy principle was Chiu $(1987,1989)$ who established a bridge between the probability domain, wherein a probability distribution of the velocity is surmised, and the physical space by deriving the cumulative probability distribution function in terms of curvilinear coordinate in the physical space. In particular Chiu predicted the two-dimensional flow velocity distribution as a function of $u_{\max }$ and of the curvilinear coordinates, representing the isovel in the flow area, as:

$u=\frac{u_{\max }}{M} \ln \left(1+\left(e^{M}-1\right) \cdot \frac{\xi-\xi_{0}}{\xi_{\max }-\xi_{0}}\right)$

where $u$ is the velocity in the longitudinal direction along the isovel $\xi ; \frac{\xi-\xi_{0}}{\xi_{\max }-\xi_{0}}$ represents the cumulative probability distribution function, in which $\xi$ is the curvilinear coordinate depending on the cross-section geometry shape and with which $u$ develops; specifically, $\xi=\xi_{\max }$ at the point where $u_{\max }$ occurs; $\xi=\xi_{0}$ at the channel bed where $u=0$. It is worth noting that the velocity increases monotonically with $\xi . M$ is the entropy parameter which can be easily estimated through the linear entropy relation (Chiu and Said, 1995):

$u_{\mathrm{m}}=\Phi(M) u_{\max }$

where

$\Phi(M)=\left(\frac{e^{M}}{1-e^{M}}-\frac{1}{M}\right)$

$u_{\mathrm{m}}$ is the mean flow velocity.

Therefore, $M$ can be assessed on the basis of the sample of pairs $\left(u_{\mathrm{m}}, u_{\max }\right)$ obtained from the velocity measurements routinely carried out at gauged river sites. It has to be pointed out, however, that Eq. (B2), for particular flow conditions, is found less accurate than Eq. (B1) (Chiu and Said, 1995; Moramarco et al., 2004). 
For wide channels $\xi=\frac{D-y}{D}$, with $y$ and $D$ depth with respect to the channel bed and maximum flow, respectively. In this case Eq. (B1) can be written in terms of y-axis as:

$$
\begin{aligned}
u(0, y)= & \frac{u_{\max }}{M} \ln \left(1+\left(e^{M}-1\right) \frac{D-y}{D-h_{u}} .\right. \\
& \left.\exp \left(1-\frac{D-y}{D-h_{u}}\right)\right)
\end{aligned}
$$

which is the basis for developing the simplified twodimensional velocity model such as proposed by Moramarco et al. (2004).

Acknowledgements. The authors are thankful to Department of Environment, Planning and Infrastructure, Umbria Region, for providing the data. The research has been funded by the PRIN 2008 program "Integration of hydraulic measurements in rivers for discharge and hydraulic resistance parameter monitoring".

Edited by: F. Fenicia

\section{References}

Aricò, C., Nasello, C. and Tucciarelli, T.: Using unsteady water level data to estimate channel roughness and discharge hydrograph, Adv. Water Res., 32, 1223-1240, doi:10.1016/j.advwatres.2009.05.001, 2009.

Aricò, C., Corato, G., Tucciarelli, T., Mefath, M. B., Petrillo, F., and Mossa, M.: Discharge estimation in open chennels by means of water level hydrographs analysis, J. Hydraul. Res., 48, 612-619, doi:10.1080/00221686.2010.507352, 2010.

Barnes A. : Roughness charactrestics of natural channels, US Geological Survey Water-Supply Paper 1849, 1967.

Beven, K. J. and Carling, P.: Velocities, roughness and dispersion in the lowland River Severn, in: Lowland Floodplain Rivers, edited by: Carling, P. and Petts, G., Wiley, New York, 1992.

Brent, R. P.: Algorithms for Minimization Without Derivatives, Prentice Hall, Englewood Cliffs, NJ, 1973.

Chiu, C. L.: Entropy and probability concepts in hydraulics, J. Hydraul. Eng.-ASCE, 113, 583-600, 1987.

Chiu, C. L.: Entropy and 2-D velocity distribution in open channels, J. Hydraul Eng., 114, 738-756, 1988.

Chiu, C. L.: Velocity distribution in open channel flow, J. Hydraul Eng., 115, 576-594, 1989.

Chiu, C. L. and Said, C. A. A.: Maximum and mean velocities and entropy in open-channel flow, J. Hydraul Eng., 121, 26-35, 1995.

Chow, V. T., Maidment, D. R., and Mays, C. W.: Applied Hydrology, McGraw-Hill, New York, 1988.

Costa, J. E., Cheng, R. T., Haeni, F. P., Melcher, N., Spicer, K. R., Hayes, E., Plant, W., Hayes, K., Teague, C., and Barrick, D.: Use of radars to monitor stream discharge by noncontact methods, Water Resour. Res., 42, W07422, doi:10.1029/2005WR004430, 2006.

Cowan, W. L.: Estimating hydraulic roughness coefficients, Agr. Eng., 37, 473-475, 1956.
De Saint Venant, B.: Théorie de mouvement non-permanant des eaux avec application aux crues des rivières et à l'introduction des marées dans leur lit, Acad. Sci. Paris CR, 73, 148-54, 237$240,1871$.

Decatur: Surface Velocity Radar (SVR) ${ }^{(\mathrm{TM})}$ User's manual, Decatur Electronics Inc., Decatur, USA, 2005.

DHI Water and Environment: Mike 11 - A Modelling System for Rivers and Channels - Reference Manual, Horsholm, Denemark, 2001.

Di Baldassarre, G. and Montanari, A.: Uncertainty in river discharge observations: a quantitative analysis, Hydrol. Earth Syst. Sci., 13, 913-921, doi:10.5194/hess-13-913-2009, 2009.

Fenton, J. D. : Calculating hydrographs from stage records, Proc. 28th IHAR Congress, Graz, Austria, 1999.

Fulton, J. and Ostrowski, J.: Measuring real-time streamflow using emerging technologies: Radar, hydroacoustics, and the probability concepts, J. Hydrol., 357, 1-10, doi:10.1016/j.jhydrol.2008.03.028, 2008.

Henderson, F. M.: Open channel flow. Macmillian Series in Civil Engineering, Macmillian, New York, 1966.

Herschy, R. W.: Streamflow measurement, 2nd Edn., E \& FN, Spon, London, 1985.

Jaynes, E. T.: Information theory and statistical mechanics, Phys. Rev., 106, 620-630, 1957.

Moramarco, T. and Singh, V. P.: Formulation of the Entropy Parameter Based on Hydraulic and Geometric Characteristics of River Cross Sections, J. Hydrol. Eng.-ASCE, 15, 852, doi:10.1061/(ASCE)HE.1943-5584.0000255, 2010.

Moramarco, T., Saltalippi, C., and Singh, V. P.: Estimation of mean velocity in natural channels based on Chiu's velocity distribution equation, J. Hydrol. Eng.-ASCE, 9, 42-50, doi:10.1061/(ASCE)1084-0699(2004)9:1(42), 2004.

Moramarco, T., Barbetta, S., Melone, F., and Burnelli, A.: Streamflow measurement methods and practical approaches for discharge assessment, FLOODMED Monitoring, forecasting and best practices for FLOOD Mitigation and prevEntion in the CADSES region, Action 2.1 Report, 1-40, 2007.

Moramarco, T., Pandolfo, C., and Singh, V. P.: Accuracy of kinematic wave and diffusion wave approximations for flood routing, J. Hydrol. Eng.-ASCE, 13, 1078-1088, doi:10.1061/(ASCE)1084-0699(2008)13:11(1089), 2008.

Moramarco, T., Saltalippi, C., and Singh, V. P.: Velocity profiles assessement in natural channel during high floods, Hydrol. Res., 42, 162-170, 2011.

Nasello, C. and Tucciarelli, T.: Dual multilevel urban drainage model, J. Hydraul. Eng.-ASCE, 131, 748-754, doi:10.1061/(ASCE)0733-9429(2005)131:9(748), 2005.

Nash, J. E. and Sutcliffe, J. V.: River flow forecasting through conceptual models, part 1: a discussion of principles, J. Hydrol., 10, 282-290, 1970.

Noto, L. and Tucciarelli, T.: DORA algorithm for network flow models with improved stability and convergence properties, J. Hydraul. Eng.-ASCE, 127, 380-391, 2001.

Pappenberger, F., Beven, K., Horritt, M., and Blazkova, S.: Uncertainty in the calibration of effective roughness parameters in HEC-RAS using inundation and downstream level observations, J. Hydrol., 302, 46-69, doi:10.1016/j.jhydrol.2004.06.036, 2005. 
Perumal, M. and Moramarco,T.: A reappraisal of discharge estimation methods using stage hydrographs, Proceedings of the International Conference on Hydrological Perspectives for Sustainable Development Vol. I, edited by: Perumal, M., Singhal, D. C., Arya, D. S., Srivastava, D. K., and Goel, N. K., Indian Institute of Technology Roorkee, Roorkee, India, 104-116, 2005.

Perumal, M., Shrestha, K. B., and Chaube, U. C.: Reproduction of Hysteresis in Rating Curves, J. Hydraul. Eng.-ASCE, 130, 870878, doi:10.1061/(ASCE)0733-9429(2004)130:9(870), 2004.

Perumal, M., Moramarco, T., Shaboo, B., and Barbetta, S.: A methodology for discharge estimation and rating curve development at ungauged sites, Water Resour. Res., 43, W02412, doi:10.1029/2005WR004609, 2007.

Plant, W. J., Keller, W. C., and Hayes, K.: Measurement of river surface currents with coherent microwave systems, IEEE T. Geosci. Remote, 43, 1242-1257, doi:10.1109/TGRS.2005.845641, 2005.

Quantum Hydrometrie: Ultrasonic Flow Measurement System, Quantum Hydrometrie, Berlin, 2002.
Shannon, C. E.: A mathematical theory of communication, Bell System Tech. J., 27, 379-423, 623-656, 1948.

Singh, V. P.: Derivation of some frequency distributions using the principle of maximum entropy (POME), Adv. Water Res., 9, 91106, doi:10.1016/0309-1708(86)90015-1, 1986.

Singh, V. P.: Hydrologic synthesis using entropy theory: review, J. Hydrol. Eng.-ASCE, 16, 421-433, doi:10.1061/(ASCE)HE.1943-5584.0000332, 2011.

Sommer: Surface flow velocity - Flow velocity sensor - RG-24, Sommer GmbH, Koblach, 2006.

Tucciarelli, T. and Termini, D.: Finite-element modeling of floodplain flows, J. Hydraul. Eng.-ASCE, 126, 416-424, doi:10.1061/(ASCE)0733-9429(2000)126:6(416), 2000.

US Army Corps of Engineers: HEC-RAS: River Analisys System - Hydraulic Reference Manual, http: //www.hec.usace.army.mil/software/hec-ras/documents/ HEC-RAS_4.0_Reference_Manual.pdf, Davis, US, 2008. 